\title{
Influence of Wound Type and Storage Duration on Susceptibility of Sweetpotatoes to Rhizopus Soft Rot
}

\author{
Gerald J. Holmes, Department of Plant Pathology, North Carolina State University, Raleigh 27695; and Richard \\ R. Stange, USDA-ARS, U.S. Horticultural Research Laboratory, Ft. Pierce, FL 34945
}

\begin{abstract}
Holmes, G. J., and Stange, R. R. 2002. Influence of wound type and storage duration on susceptibility of sweetpotatoes to Rhizopus soft rot. Plant Dis. 86:345-348.

Susceptibility of stored sweetpotato roots (cvs. Beauregard and Hernandez) to Rhizopus soft rot caused by Rhizopus stolonifer was tested at 4- to 6-week intervals over a storage period of 335 days in 1998-1999 (year 1) and 1999-2000 (year 2). In each experiment, roots were wounded by four methods (puncture, bruise, broken, and scrape), inoculated with freshly harvested spores from 4- to 10-day-old cultures, and compared with a nonwounded but inoculated control for their susceptibility to decay. Roots were totally resistant to infection after harvest for 60 days in year 1 and 30 days in year 2 . The bruise wound type was most commonly associated with infection, with disease incidence peaking 100 and 175 days after harvest in years 1 and 2, respectively. Inoculation by the puncture method followed a similar pattern in Hernandez but was ineffective in Beauregard. Following the peak in disease incidence at 100 or 175 days, susceptibility of roots declined to levels comparable to that of freshly harvested roots. This period of heightened susceptibility was longer in Hernandez than in Beauregard. The effects of injury types broken and scrape were more variable and did not show the same trend in both years.
\end{abstract}

In North Carolina, sweetpotatoes are harvested between August and November and stored for up to 10 months (14). Prior to storage, roots are cured at $29^{\circ} \mathrm{C}$ and $95 \%$ relative humidity for approximately 4 days. Curing promotes rapid healing of wounds that commonly occur at harvest and prevents losses due to postharvest disease. Roots are prepared for shipment by removing them from storage, washing and grading on a packing line, where fresh injuries occur. Abrasions and bruises occur during the initial dumping of roots into a wash tank as well as subsequent drops and corners in the packing line. In addition, root ends are manually broken off during the grading process, so that they conform more closely to industry and consumer demands of size and shape.

Rhizopus soft rot is the most destructive and widespread postharvest disease of sweetpotato in the United States and worldwide $(2,4,5,10)$. Two species of Rhizopus are known to cause the disease: $R$. stolonifer (Ehrenb.:Fr.) Vuill. (Syn. $R$. nigricans Ehrenb.) is the most common, followed by $R$. arrhizus A. Fisher (syns. $R$.

Corresponding author: G. J. Holmes

E-mail: gerald_holmes@ncsu.edu

Accepted for publication 27 November 2001.

Publication no. D-2002-0128-02R

(C) 2002 The American Phytopathological Society oryzae Went \& Prinsen-Geerligs and $R$. tritici K. Saito). In susceptible cultivars, $R$. stolonifer can rot an entire storage root in 3 to 4 days at $15^{\circ} \mathrm{C}$. Development of Rhizopus soft rot requires wounds for penetration and establishment of the pathogen $(1,3)$. Srivastava and Walker (13) demonstrated that the type of wound is very important to successful establishment of the pathogen. Generally, it is thought that wounds resulting from crushing of host tissue are most likely to release nutrients from the plant cells that can be utilized by the fungus prior to infection. Consequently, the greatest losses due to Rhizopus soft rot occur following the handling operations of bedding, harvesting, and packing, where injury is unavoidable. While losses due to the disease may be expected in cases of severe mishandling, there are also many cases when it seems to occur sporadically and unpredictably.

Anecdotal evidence suggests that resistance to Rhizopus soft rot declines with time in storage; however, to our knowledge, a systematic study of this reputed phenomenon has not been conducted. Our purpose was to determine the influence of wounding and genetic resistance in the development of Rhizopus soft rot and to see if changes in susceptibility occur over time.

\section{MATERIALS AND METHODS}

Cultivars Beauregard and Hernandez were used in this study because of their widespread commercial use and because
Hernandez is known to be more susceptible than Beauregard. Roots were obtained from two commercial sweetpotato growers in eastern North Carolina. In 1998 (year 1), roots of cvs. Beauregard and Hernandez were harvested from separate fields on 21 October and 13 October, respectively. In 1999 (year 2), roots of cvs. Beauregard and Hernandez were harvested from separate fields on 29 October and 1 November, respectively. Roots were cured $\left(29^{\circ} \mathrm{C}\right.$ and $95 \%$ relative humidity for 4 days) immediately following harvest and stored (13 to $15.5^{\circ} \mathrm{C}$ ) in industry-standard, 40-bushel $(1,409$-liter) wood bins. Bins were stored in a commercial storage facility throughout the duration of the experiment (all roots, same facility, both years). Roots of each cultivar were removed from storage, gently washed by hand in tap water, and allowed to dry at room temperature prior to inoculation.

The experiment was conducted nine times in year 1 at approximately 4-week intervals and seven times in year 2 at approximately 6-week intervals. In each experiment, 500 roots of each cultivar were used (5 treatments, 5 replicates, 20 roots per replicate). Fiberboard cartons/plastic crates were stacked in one $5 \times 5$ Latin Square design for each cultivar. Percent decay for each replicate was calculated as the number of roots decayed out of 20 total roots. Percent data were arcsine-transformed in order to normalize the variance. Differences in mean percent decay for each treatment were tested by analysis of variance (ANOVA) using the SAS General Linear Model Procedure (PROC GLM) (SAS Institute, Cary, NC). Noninoculated controls for both cultivars were not included in the ANOVA in order to meet the assumption of homogeneity of variances (very few decayed roots resulted in the controls). Mean separation was performed by Fisher's (protected) LSD.

Inoculum. Isolate $\mathrm{NC}-1$ of $R$. stolonifer was isolated from a decaying sweetpotato storage root, single-spored, and maintained on silica gel at approximately $5^{\circ} \mathrm{C}$ (12). For inoculum production, a few silica gel crystals were transferred to petri dishes containing potato dextrose agar (PDA) and incubated for 4 to 6 days at $25^{\circ} \mathrm{C}$. Spores were harvested by flooding culture dishes with $0.01 \%$ Triton X-100 (Sigma Chemical 
Co., St. Louis, MO) and gently scraping them with a glass rod to dislodge spores. The resulting spore suspension was filtered through four layers of cheesecloth to remove hyphal fragments and adjusted to $10^{6}$ spores per $\mathrm{ml}$ on the basis of optical density $\left(A_{425}=0.05\right)(11)$. A fresh spore suspension was prepared from silica gel for each of the 16 experiments.

Inoculation procedures. Based on field observations, preliminary experiments, and other published reports $(2,4,7,13)$, four wound types were selected: (i) scrape, (ii) puncture, (iii) bruise, and (iv) broken. The details of each wound type are given in Table 1. Roots were injured on opposite sides of the midsection, two injuries per root. Inoculum was introduced by brushing the spore suspension over the wounded area using a paintbrush (38 $\mathrm{mm}$ wide). Inoculated roots were stored at 13 to $15^{\circ} \mathrm{C}$ in fiberboard cartons (year 1) or plastic, stackable crates (year 2) and evaluated for disease incidence at 10 days. Roots were considered decayed if soft rot had developed from the point of inoculation. Preliminary experiments showed that little or no decay resulted from the same wound types inflicted on washed and unwashed roots that were not inoculated.

\section{RESULTS}

Effect of cultivar. Individual roots showed either extensive decay or no decay. In Hernandez, decay typically affected the entire root within 4 to 6 days, whereas in Beauregard, decay typically affected 30 to $50 \%$ of the root at 10 days. With a few minor exceptions, disease incidence was greatest in Hernandez regardless of the injury type or date of inoculation. The difference between cultivars was greatest with puncture inoculation (Tables 2 and 3 , Fig. 1).

Effect of wound type. Injuring roots by the bruise method resulted in the highest levels of decay for both cultivars. Decay incidence peaked at 100 and 175 days in years 1 and 2, respectively. The peaks were followed by a sharp decline in disease incidence. The puncture method of wounding was associated with high levels of decay in Hernandez but not in Beauregard (Tables 2 and 3, Fig. 1).

Roots injured by the broken or scrape methods were associated with a variable

Table 1. Inoculation methods ${ }^{y}$

\begin{tabular}{|c|c|c|}
\hline Wound type & Tool used & Description of injury ${ }^{z}$ \\
\hline Scrape & Grater/zester & $\begin{array}{l}2 \text { to } 4 \mathrm{~cm} \text { wide, } 1 \text { to } 2 \mathrm{~mm} \text { deep, and } 6 \text { to } 10 \mathrm{~cm} \text { long } \\
\text { depending on the size and shape of the root }\end{array}$ \\
\hline Puncture & Wood screw & $\begin{array}{l}\text { No. } 7 \times 1 \text { inch, flat-head, slotted }(21 \mathrm{~mm} \text { deep, } 4 \\
\text { mm diameter); screw held at tip of pliers and in- } \\
\text { serted straight into tissue and immediately removed }\end{array}$ \\
\hline Bruise & $\begin{array}{l}\text { Wood dowel driven by } \\
\text { elastic band }\end{array}$ & $\begin{array}{l}\text { Rapid impact of } 8 \text {-mm-diameter wood cylinder, } 1 \\
\text { mm deep; visible injury confined to dimensions of } \\
\text { cylinder and its depth; impact produced an average } \\
\text { force of } 1 \mathrm{~kg} / \mathrm{cm}^{2}\end{array}$ \\
\hline Broken & By hand & $\begin{array}{l}\text { Root tip broken off at proximal/distal end exposing } \\
\text { approximately } 3 \text { to } 6 \mathrm{~cm} \text { diameter internal tissue } \\
\text { depending on size and shape of root }\end{array}$ \\
\hline Nonwounded & NA & NA \\
\hline
\end{tabular}

response depending on cultivar and year. With a few minor exceptions, disease incidence was greater in the broken injury. Decay incidence from both broken and scrape injuries increased between 200 and 325 days in 1999, but this trend did not repeat in 2000 (Tables 2 and 3, Fig. 1). No decay occurred regardless of the inoculation method for 60 and 30 days in years 1 and 2 , respectively.

\section{DISCUSSION}

Susceptibility of sweetpotato roots to soft rot caused by $R$. stolonifer did not increase with increased storage duration. Roots were totally resistant to infection for at least 30 to 60 days after harvest regardless of the wound type. When roots were wounded by the bruise method and inoculated, disease incidence peaked 100 and 175 days after harvest in years 1 and 2, respectively. After peaking, disease incidence declined to levels similar to freshly harvested roots.

The observed increase in susceptibility may be related to changes in host physiology during storage. Hasselbring and Hawkins (6) showed that sweetpotatoes at harvest are high in starch content and low in sugar content. During storage, starch content gradually decreases and sugar content increases up until about March, when there is a slight reversal of the process. Harter and Weimer (4) concluded that sugar content is not a "controlling factor" in Rhizopus soft rot because they were able to incite rot in sweetpotatoes at any stage of storage with equal ease. If sugar content is a controlling factor in susceptibility to Rhizopus soft rot, there should be a strong correlation between it and susceptibility to disease, not the sharp decline that we documented in both years.

Earlier workers showed a relationship between soil temperatures at harvest and levels of decay and weight loss in storage. This was associated with conditions (temperature and relative humidity) during the

Table 2. Percent decay in sweetpotato during 1998-1999 storage period (year 1)

\begin{tabular}{|c|c|c|c|c|c|c|c|c|c|}
\hline \multirow{2}{*}{$\begin{array}{l}\text { Cultivar and } \\
\text { wound type }\end{array}$} & \multicolumn{9}{|c|}{ Inoculation date } \\
\hline & 27 Oct 98 & 24 Nov 98 & 23 Dec 98 & 29 Jan 99 & 24 Feb 99 & 28 May 99 & 7 Jul 99 & 17 Aug 99 & 13 Sep 99 \\
\hline \multicolumn{10}{|l|}{ Hernandez } \\
\hline Noninjured ${ }^{\mathrm{y}}$ & $0^{\mathrm{z}}$ & 0 & 0 & 1 & 2 & 0 & 0 & 2 & 0 \\
\hline Puncture & 0 & 0 & 0 & $85 \mathrm{~b}$ & $64 \mathrm{~b}$ & $4 \mathrm{~cd}$ & $3 \mathrm{de}$ & $3 \mathrm{~d}$ & $14 \mathrm{~cd}$ \\
\hline Bruise & 0 & 0 & 1 & $92 \mathrm{a}$ & $88 \mathrm{a}$ & $21 \mathrm{~b}$ & $6 \mathrm{~cd}$ & $3 \mathrm{~d}$ & $20 \mathrm{cb}$ \\
\hline Broken & 0 & 0 & 0 & $14 \mathrm{c}$ & $44 \mathrm{c}$ & $39 \mathrm{a}$ & $63 \mathrm{a}$ & $82 \mathrm{a}$ & $73 \mathrm{a}$ \\
\hline Scrape & 0 & 0 & 0 & $16 \mathrm{c}$ & $43 c$ & $8 \mathrm{c}$ & $0 \mathrm{e}$ & $18 \mathrm{~b}$ & $15 \mathrm{bc}$ \\
\hline \multicolumn{10}{|l|}{ Beauregard } \\
\hline Noninjured $\mathrm{d}^{\mathrm{y}}$ & 0 & 0 & 0 & 0 & 2 & 0 & 1 & 1 & 1 \\
\hline Puncture & 0 & 0 & 0 & $1 \mathrm{~d}$ & $1 \mathrm{e}$ & $1 \mathrm{~d}$ & $9 \mathrm{c}$ & $5 \mathrm{~cd}$ & $6 \mathrm{~d}$ \\
\hline Bruise & 0 & 1 & 0 & $78 \mathrm{~b}$ & $17 \mathrm{~d}$ & $0 \mathrm{~d}$ & $6 \mathrm{~cd}$ & $2 \mathrm{~d}$ & $10 \mathrm{~cd}$ \\
\hline Broken & 0 & 0 & 0 & $0 \mathrm{~d}$ & $1 \mathrm{e}$ & $8 \mathrm{c}$ & $21 \mathrm{~b}$ & $22 \mathrm{~b}$ & $29 \mathrm{~b}$ \\
\hline Scrape & 0 & 0 & 0 & $3 d$ & $6 \mathrm{de}$ & $4 \mathrm{~cd}$ & $20 \mathrm{~b}$ & $15 \mathrm{bc}$ & $20 \mathrm{bc}$ \\
\hline$P=$ & $\ldots$ & $\ldots$ & $\ldots$ & $<0.0001$ & $<0.0001$ & $<0.0001$ & $<0.0001$ & $<0.0001$ & $<0.0001$ \\
\hline LSD & $\ldots$ & $\ldots$ & $\ldots$ & 0.08 & 0.14 & 0.10 & 0.08 & 0.09 & 0.12 \\
\hline
\end{tabular}

${ }^{y}$ Noninjured controls were not included in the analysis of variance.

${ }^{z}$ Values represent the mean of five replicates; treatments followed by the same letter within a column are not significantly different (Fisher's protected LSD, $P=0.05$ ); although values presented are percentages, analysis of variance and mean separation was performed on arcsine-transformed data. 
curing period. In a short review of Rhizopus soft rot, Moline and Lipton (10) mention a report of a positive correlation between weight loss during curing at $26^{\circ} \mathrm{C}$ and decay development after 5 months of storage at $15^{\circ} \mathrm{C}$. However, Lutz (8) showed that losses from decay in roots stored for 4 or 5 months following a 4-day curing period at $84^{\circ} \mathrm{F}\left(29^{\circ} \mathrm{C}\right)$ were no greater than those following 7,10 , or 14 days of curing at the same temperature. It is well established that longer periods of curing result in greater moisture loss (9), but the correlation of moisture loss to increased decay is not well established.

Wound type greatly influenced disease incidence. The bruise wound type was most commonly associated with infection. The association of the broken and scrape injury types with infection were more vari- able and did not show the same trend in both years.

Clark and Hoy (2) compared bruise and puncture wound types and found that soft rot incidence was greater when inoculum was introduced by the puncture method. They found that Hernandez had four times the level of decay when inoculated by the puncture method compared with their impact/bruise method. We found disease inci-

Table 3. Percent decay in sweetpotato during 1999-2000 storage period (year 2)

\begin{tabular}{|c|c|c|c|c|c|c|c|}
\hline \multirow{2}{*}{$\begin{array}{l}\text { Cultivar and } \\
\text { wound type }\end{array}$} & \multicolumn{7}{|c|}{ Inoculation date } \\
\hline & 2 Dec 99 & 4 Feb 00 & 21 Mar 00 & 26 Apr 00 & 30 Jun 00 & 2 Aug 00 & 25 Sep 00 \\
\hline \multicolumn{8}{|l|}{ Hernandez } \\
\hline Noninjured $\mathrm{d}^{\mathrm{y}}$ & $0^{\mathrm{z}}$ & 11 & 0 & 7 & 0 & 0 & 0 \\
\hline Puncture & $0 \mathrm{~b}$ & $24 \mathrm{ab}$ & $39 \mathrm{~b}$ & $78 \mathrm{~b}$ & $13 \mathrm{c}$ & $5 \mathrm{~b}$ & $2 \mathrm{~b}$ \\
\hline Bruise & $1 \mathrm{~b}$ & $40 \mathrm{a}$ & $83 \mathrm{a}$ & 99 a & $59 \mathrm{a}$ & $38 \mathrm{a}$ & $14 \mathrm{a}$ \\
\hline Broken & $1 \mathrm{~b}$ & $23 \mathrm{ab}$ & $36 \mathrm{~b}$ & $38 \mathrm{c}$ & $23 \mathrm{~b}$ & $1 \mathrm{~b}$ & $2 \mathrm{~b}$ \\
\hline Scrape & $0 \mathrm{~b}$ & $12 \mathrm{bc}$ & $15 \mathrm{c}$ & $11 \mathrm{~d}$ & $1 \mathrm{~d}$ & $0 \mathrm{~b}$ & $0 \mathrm{~b}$ \\
\hline \multicolumn{8}{|l|}{ Beauregard } \\
\hline Noninjured $\mathrm{y}$ & 1 & 1 & 1 & 0 & 0 & 0 & 0 \\
\hline Puncture & $0 \mathrm{~b}$ & $1 \mathrm{~d}$ & $7 \mathrm{c}$ & $0 \mathrm{e}$ & $0 \mathrm{~d}$ & $0 \mathrm{~b}$ & $0 \mathrm{~b}$ \\
\hline Bruise & $4 \mathrm{a}$ & $7 \mathrm{~cd}$ & $37 \mathrm{~b}$ & $9 \mathrm{~d}$ & $0 \mathrm{~d}$ & $0 \mathrm{~b}$ & $0 \mathrm{~b}$ \\
\hline Broken & $0 \mathrm{~b}$ & $1 \mathrm{~d}$ & $5 \mathrm{c}$ & $8 \mathrm{~d}$ & $2 \mathrm{~d}$ & $1 \mathrm{~b}$ & $1 \mathrm{~b}$ \\
\hline Scrape & $1 \mathrm{~b}$ & $13 \mathrm{bc}$ & $7 \mathrm{c}$ & $4 \mathrm{de}$ & $1 \mathrm{~d}$ & $4 \mathrm{~b}$ & $0 \mathrm{~b}$ \\
\hline$P=$ & 0.0009 & 0.0010 & $<0.0001$ & $<0.0001$ & $<0.0001$ & $<0.0001$ & $<0.0001$ \\
\hline LSD & 0.018 & 0.17 & 0.14 & 0.11 & 0.10 & 0.13 & 0.039 \\
\hline
\end{tabular}

${ }^{y}$ Noninjured controls were not included in the analysis of variance.

$\mathrm{z}$ Values represent the mean of five replicates; treatments followed by the same letter within a column are not significantly different (Fisher's protected LSD, $P=0.05$ ); although values presented are percentages, analysis of variance and mean separation was performed on arcsine-transformed data.

1998-1999
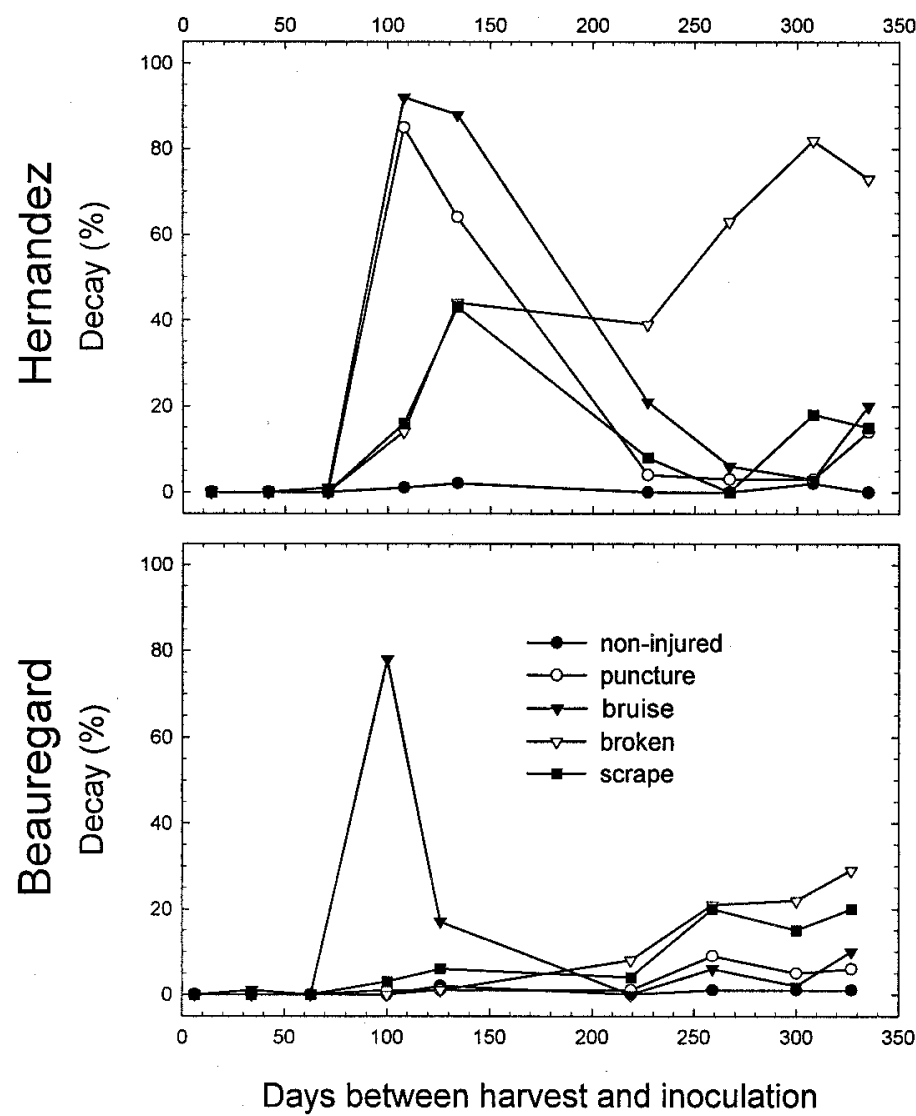

$1999-2000$
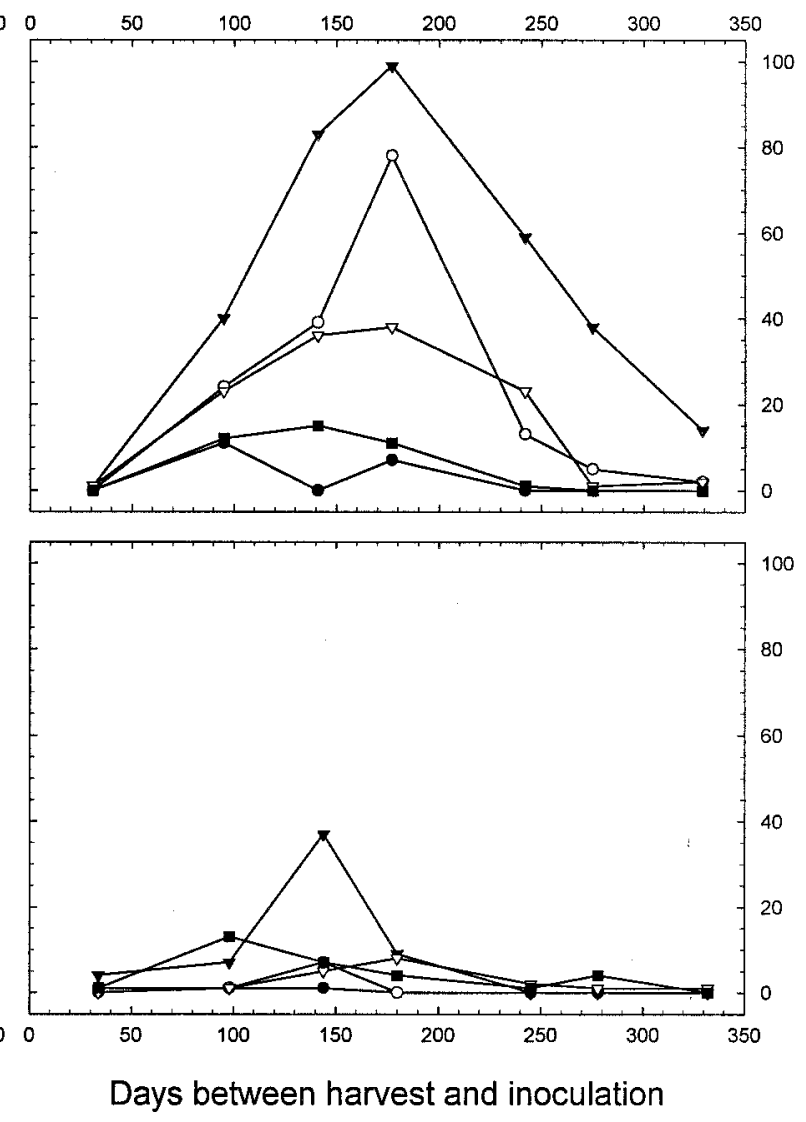

Fig. 1. Influence of wound type and storage duration on susceptibility of sweetpotatoes cvs. Hernandez and Beauregard to Rhizopus soft rot. 
dence to be greater when inoculum was introduced by the bruise method. Moreover, we achieved similar levels of decay with both puncture and bruise methods, with the bruise method consistently resulting in higher levels of decay. This may be explained by the difference in the method of producing the bruise. Clark and Hoy allowed roots to drop $1 \mathrm{~m}$ from the end of a bench into crates. While this more closely approximates wounding that occurs on a packing line, it gives little control over the location on the root where impact occurs, or angle of the root at impact (which would determine area of impact and force per unit area). Our bruise wound was made using reproducible force and area at predetermined locations on the root (Table 1).

We observed cultivar-specific differences in the severity of decay, with Hernandez being more susceptible than Beauregard. While this was also observed by Harter and Weimer (4), it was not observed by Clark and Hoy (2), who also used these cultivars.

Harter and Weimer (4) did not achieve successful infection using spores as inoculum, regardless of wound type, cultivar, or storage duration. They concluded that active mycelium was necessary for successful infection. However, their "well method" of inoculation (i.e., actively growing mycelium from a sweetpotato substrate inserted into a 1 - to $2-\mathrm{cm}$ well) may have been sufficiently extreme to overcome any host defense mechanism. We achieved successful infection using freshly harvested spores from 4- to 10day-old cultures.

Our results indicate that it may be possible to effectively manage Rhizopus soft rot through the use of resistant cultivars and handling practices that minimize wounding, especially bruising. An awareness of the changes in susceptibility to Rhizopus soft rot may help minimize decay problems. For example, dicloran (Botran 75W) may not be necessary during the first few months of packing, since roots did not succumb to decay by any inoculation method. High susceptibility between 100 and 175 days after harvest re-emphasizes the need for gentle handling.

Characterization of changes in root physiology during the entire storage period are necessary to elucidate the mechanism(s) behind the observed changes in disease susceptibility. An understanding of this process may allow for predicting root susceptibility to Rhizopus soft rot and provide insights for improving disease control.

\section{ACKNOWLEDGMENTS}

The financial support of the North Carolina Sweetpotato Commission and technical assistance of M. J. Adams are gratefully acknowledged. We thank W. Jester for assistance in locating sweetpotatoes and grower cooperators. We thank Clay Strickland and Kendall Hill for donating sweetpotatoes and Tull-Hill Farms for use of their excellent curing and storage facilities.

\section{LITERATURE CITED}

1. Clark, C. A. 1992. Postharvest diseases of sweet potatoes and their control. Postharvest News Inf. 3:75N-79N.

2. Clark, C. A., and Hoy, M. W. 1994. Identifica- tion of resistance in sweetpotato to Rhizopus soft rot using two inoculation methods. Plant Dis. 78:1078-1082.

3. Clark, C. A., and Moyer, J. W. 1988. Compendium of Sweet Potato Diseases. American Phytopathological Society, St. Paul, MN.

4. Harter, L. L., and Weimer, J. L. 1918. Sweetpotato storage rots. J. Agric. Res. 15:337-368.

5. Harter, L. L., and Weimer, J. L. 1921. Susceptibility of the different varieties of sweet potatoes to decay by Rhizopus nigricans and Rhizopus tritici. J. Agric. Res. 22:511-515.

6. Hasselbring, H., and Hawkins, L. A. 1915. Physiological changes in sweet potatoes during storage. J. Agric. Res. 3(4):331-342.

7. Lauritzen, J. I. 1935. Factors affecting infection and decay of sweet-potatoes by certain storage rot fungi. J. Agric. Res. 50:285-329.

8. Lutz, J. M. 1951. Influence of temperature and length of curing period on keeping quality of Porto Rico sweetpotatoes. Proc. Am. Soc. Hortic. Sci. 59:421-425.

9. McCombs, C. L., and Pope, D. T. 1958. The effect of length of cure and storage temperature upon certain quality factors of sweet potatoes. Am. Soc. Hortic. Sci. 72:426-434.

10. Moline, H. E., and Lipton, W. J. 1987. Market diseases of beets, chicory, endive, escarole, globe artichokes, lettuce, rhubarb, spinach, and sweetpotatoes. U.S. Dep. Agric. Agric. Handb. No. 155.

11. Morris, S. C., and Nicholls, P. J. 1978. An evaluation of optical density to estimate fungal spore concentrations in water suspensions. Phytopathology 68:1240-1242.

12. Perkins, D. D. 1962. Preservation of Neurospora stock cultures with anhydrous silica gel. Can. J. Microbiol. 8:591-594.

13. Srivastava, D. N., and Walker, J. C. 1959. Mechanisms of infection of sweet potato roots by Rhizopus stolonifer. Phytopathology 49:400-406.

14. Wilson, L. G., and Averre, C. W. 1989. Growing and marketing quality sweet potatoes. North Carolina State University, Publ. AG-09. 